\title{
Graft versus tumor effect against neuroblastoma: a case report with long-term survival and a review of the literature
}

\author{
Akihiro Hoshino, Keiko Nomura, and Hirokazu Kanegane \\ Department of Pediatrics, Graduate School of Medicine and Pharmaceutical Sciences, University of Toyama
}

Some studies have reported the graft versus tumor (GVT) effect against neuroblastoma, but it remains unclear whether this effect is associated with long-term survival in neuroblastoma. Here, we describe a 13-year-old boy who has survived for 7 years following allogeneic hematopoietic stem cell transplantation (HSCT) for refractory neuroblastoma. The patient received conventional therapy, but there were residual tumor cells in bone marrow. Hence, he received allogeneic HSCT. Although he did not achieve complete remission just after HSCT, tumor markers were reduced during severe chronic graft versus host disease (cGVHD). This indicates the possibility that the GVT effect against neuroblastoma is associated with cGVHD and it can improve long-term outcome. (Journal of Hematopoietic Cell Transplantation 3(3): 97-101, 2014.)

\section{Introduction}

Neuroblastoma is the most common extracranial solid tumor in children. ${ }^{1}$ Although its outcome has improved because of the progress of intensive therapy, patients with refractory or relapsed neuroblastoma still have a poor prognosis. ${ }^{2}$ More intensive chemotherapy may reach an effective limit, while a high incidence of late adverse effects has been noted. ${ }^{3}$

Allogeneic hematopoietic stem cell transplantation (allo-HSCT) is expected not only to have an anti-tumor effect due to the conditioning regimen but also to have an immunological anti-tumor effect due to donor lymphocytes. There is a wide acceptance of the occurrence of the graft versus leukemia (GVL) effect against chronic myelogenous leukemia. ${ }^{4,5}$ Patients with graft versus host disease (GVHD) have a lower probability of relapse than patients without it, ${ }^{4}$ and donor lymphocyte infusion (DLI) can successfully induce remission in relapsed patients after $\mathrm{HSCT}^{5}$ Allogeneic graft versus tumor (GVT) effect has also been reported against certain kinds of solid tumor, mostly against renal cell carcinoma. ${ }^{6}$
Some studies have reported the GVT effect in patients with neuroblastoma. ${ }^{7}$ However, allo-HSCT for neuroblastoma is being investigated and not widely performed. A safe and efficient way to induce the GVT effect is unclear. Previous studies matching allogeneic versus autologous HSCT (autoHSCT) showed no difference in survival and no correlation between GVHD and survival. ${ }^{8}$ Furthermore, some patients died even if the GVT effect was suggested. ${ }^{9}$ Although longterm survival is the absolute goal of treatment, whether the GVT effect is associated with long-term survival remains unclear. We present a patient with refractory neuroblastoma who demonstrated the possibility of the GVT effect, and review the literature. To our knowledge, our patient is the longest survivor reported to date, and the clinical course indicates that the GVT effect can improve the long-term outcomes of patients with neuroblastoma.

\section{Case report}

A 5-year-old boy demonstrated abdominal sympathetic ganglion mass lesion with metastasis of the para-aortic lymph nodes, bone marrow and multiple bones with elevated urinary

Submitted April 15, 2014; Accepted June 8, 2014

Key words: graft versus host disease, graft versus tumor, hematopoietic stem cell transplantation, Neuroblastoma

Correspondence: Akihiro Hoshino, MD, Department of Pediatrics, Graduate School of Medicine and Pharmaceutical Sciences, University of Toyama, 2630 Sugitani, Toyama, Toyama 930-0194, Japan. E-mail: nrb52665@yahoo.co.jp.

dx.doi.org/10.7889/hct. 3.97 (C) The Japan Society for Hematopoietic Cell Transplantation. 
vanillyl mandelic acid (VMA) to $287 \mu \mathrm{g} / \mathrm{mg}$ creatinine, urinary homovanillic acid (HVA) to $225 \mu \mathrm{g} / \mathrm{mg}$ creatinine and serum neuron-specific enolase (NSE) to $328 \mathrm{ng} / \mathrm{mL}$; he was diagnosed with stage 4 neuroblastoma. Pathological studies showed poorly differentiated neuroblastoma with unfavorable histology. $N M Y C$ gene was not amplified. The patient was treated with 4 courses of the New A1 protocol and 1 course of the 98A3 protocol, which included cyclophosphamide, pirarubicin, etoposide, vincristine and cisplatin, but the response was partial. The patient subsequently received total surgical resection of the primary tumor and irradiation of the tumor bed. However, ${ }^{123}$ I-meta-iodobenzyl-guanidine (MIBG) scintigraphy revealed the retention of abnormal uptake in multiple bones, suggesting residual tumor cells in bone marrow. Therefore, allogeneic bone marrow transplantation from a human leukocyte antigen (HLA)matched sibling donor was performed instead of the high-dose chemotherapy with auto-HSCT. The conditioning regimen included melphalan $\left(180 \mathrm{mg} / \mathrm{m}^{2}\right)$, etoposide $\left(500 \mathrm{mg} / \mathrm{m}^{2}\right)$, carboplatin $\left(1,500 \mathrm{mg} / \mathrm{m}^{2}\right)$ and total body irradiation (10 Gy). The patient received $3.0 \times 10^{8}$ nucleated cells $/ \mathrm{kg}$ and $5.0 \times 10^{6}$ $\mathrm{CD} 34^{+}$cells $/ \mathrm{kg}$. Methylprednisolone was used for GVHD prophylaxis because of allergy to intravenous tacrolimus and cyclosporine A. Engraftment was achieved with neutrophils at $\geq 0.5 \times 10^{9} / \mathrm{L}$ on day +17 and platelets at $\geq 50 \times 10^{9} / \mathrm{L}$ on day +31 . Complete chimerism in peripheral blood was confirmed on day +42 using multiplex amplification of short tandem repeat markers. He developed grade I acute GVHD (aGVHD), which was rapidly resolved with oral tacrolimus. At 6 months after HSCT, he developed moderate chronic GVHD (cGVHD) (skin, mouth and liver), and received oral tacrolimus and prednisolone. However, at 18 months after HSCT, he exhibited sclerodermatous changes of the skin and muscle contraction, resulting in arthrogryposis. Tacrolimus was changed to mycophenolate mofetil because of druginduced pancreatitis and diabetes mellitus, and his symptoms improved gradually.

The patient had remaining disease with elevated urinary HVA and abnormal uptake of ${ }^{123}$ I-MIBG in multiple bones one month after HSCT (Figure 1). However, the normalization of urinary HVA levels was observed during cGVHD. The levels were increased after the resolution of cGVHD, but they were dramatically decreased after the reoccurrence of severe cGVHD. He has been well for 7 years after HSCT with reduced uptake of ${ }^{123}$ I-MIBG.

\section{Discussion}

Table 1 summarizes reported cases of neuroblastoma suggestive of the GVT effect following allo-HSCT. Inoue et al. ${ }^{7}$ reported a patient with metastatic neuroblastoma who showed tumor regression over 3 years after HLA haploidentical HSCT. This phenomenon was just incidental, but allo-HSCT was subsequently performed intentionally, including haploidentical HSCT or DLI, in the expectation of achieving a strong immunological anti-tumor effect. ${ }^{9}$ In addition, a reduced-intensity conditioning regimen was performed, separate from the idea of eradicating the tumor by myeloablative conditioning. Hirayama et al. and Marebelle et al. reported remission following the development of GVHD after the withdrawal of immunosuppressive drugs or DLI. However, because recovery of lymphocytes was typically delayed for months after HSCT, rapid progression of the tumor before the appearance of the GVT effect is a serious issue, ${ }^{9}$ particularly in patients with a significant tumor burden. Because tumor cells are often resistant to chemotherapy in patients with refractory or relapsed neuroblastoma, highdose ${ }^{131} \mathrm{I}$-MIBG treatment was performed as the conditioning regimen. As initial treatment for newly diagnosed advanced neuroblastoma, Goi et al. reported 3 successful patients who received tandem transplantation consisting of auto-HSCT followed by allogeneic cord blood transplantation (CBT). Recently, Kanold et al. performed donor NK cell infusion in the expectation of an NK cell-mediated GVT effect.

We have reported a patient with residual neuroblastoma who survived for a long period after allo-HSCT. Decreased urinary HVA levels seem to be associated with recurrent cGVHD, and the levels were dramatically decreased with reduced uptake of ${ }^{123}$ I-MIBG after the occurrence of severe cGVHD. Because he did not receive any treatment for neuroblastoma after HSCT, his clinical course suggested the existence of the GVT effect and the association between cGVHD and the GVT effect. Furthermore, it is speculated that cGVHD may have contributed to his long-term survival. Chronic GVHD is a strong factor for the GVL effect against leukemia, which is associated with a lower probability of relapse and long-term survival. ${ }^{410}$ In patients with certain kinds of solid tumor, cGVHD is associated with long-term survival. ${ }^{11,12}$ Although a study of neuroblastoma showed no advantage of GVHD, it should be noted that statistical analysis of relapse evaluating the impact of cGVHD could not be performed because of the low incidence of cGVHD. ${ }^{8}$ 


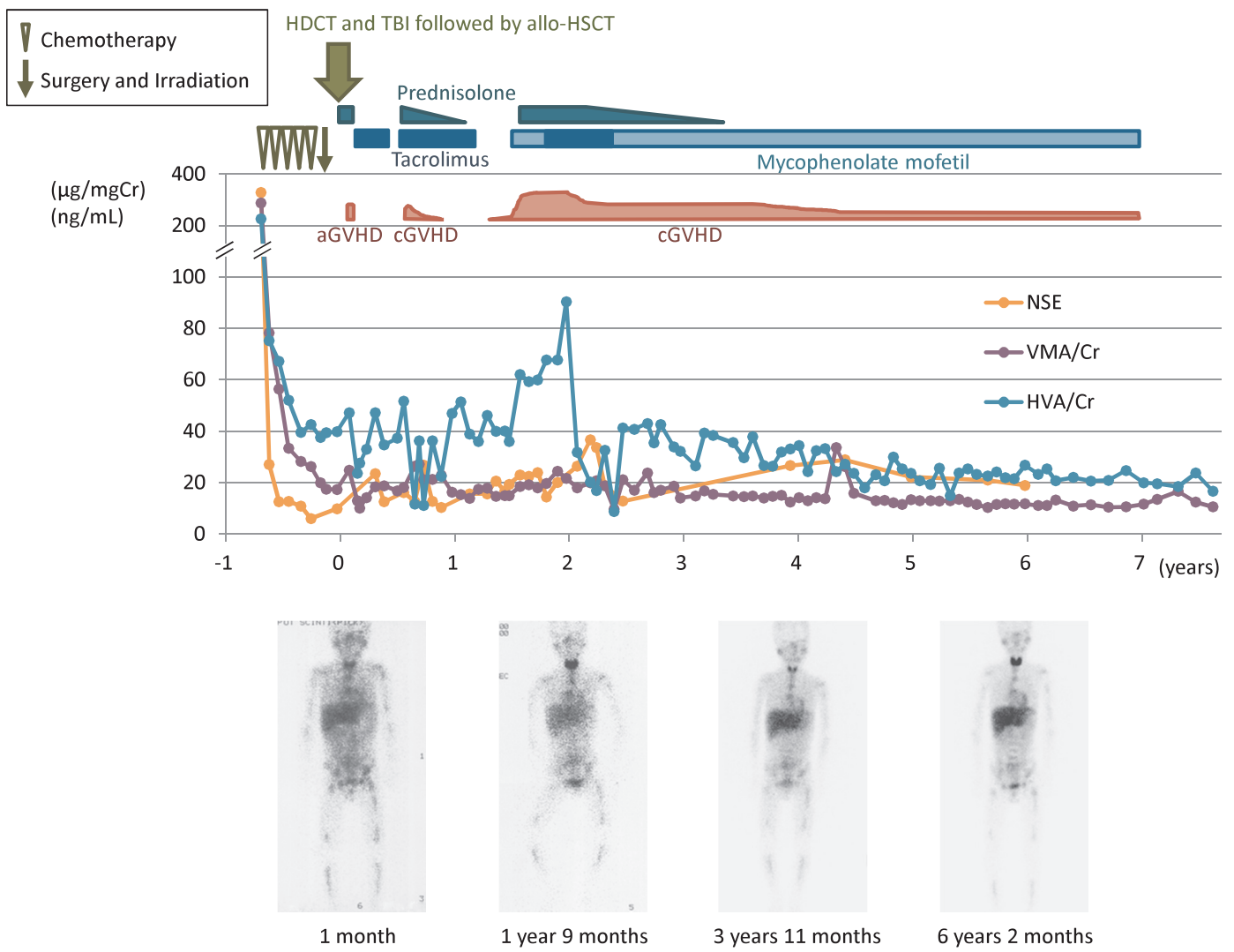

Figure 1 Clinical course

Increased urinary homovanillic acid (HVA) levels were persistent after allogeneic hematopoietic stem cell transplantation (allo-HSCT), but the normalization of urinary HVA levels was observed during chronic graft versus host disease (cGVHD) between 7 and 10 months after allo-HSCT. Although the levels were increased after the resolution of cGVHD, they were dramatically decreased after the reoccurrence of severe cGVHD. Abnormal uptake of ${ }^{123}$ I-meta-iodobenzyl-guanidine in multiple bones decreased gradually.

Although there are only a few case reports and small series suggestive of the GVT effect against neuroblastoma, the GVT effect is most probably mediated by donor T cells. While minor histocompatibility antigens or tumor-associated antigens are identified as possible targets of the GVT effect against other solid tumors or hematological malignancies, ${ }^{13}$ actual immune mechanisms are unclear in neuroblastoma. However, IFN- $\gamma$-producing $\mathrm{CD} 8^{+} \mathrm{T}$ cells were increased in a patient with neuroblastoma showing tumor regression after donor $\mathrm{CD}^{+}{ }^{+}$lymphocyte infusion, ${ }^{9}$ and a murine model of neuroblastoma demonstrated that the GVT effect was primed by major histocompatibility disparity and targeted tumor-associated antigens. ${ }^{14}$ Because our patient received an allo-HSCT from an HLA-matched sibling donor, there is a possibility that minor histocompatibility antigens or tumor-associated antigens were targets. The degree of HLA expression on the tumor cells or T-cell recognition and its duration seem to vary among cases. ${ }^{15}$ An accumulation of cases and determination of a safe and efficient way to induce the GVT effect might lead to improvement of the outcome of neuroblastoma. Furthermore, further advantages could improve not only allo-HSCT but also other immunomodulatory therapies.

\section{Author contributions}

$\mathrm{AH}$ and $\mathrm{HK}$ analyzed the data and wrote the manuscript. $\mathrm{KN}$ and HK have followed the patient. All authors read and approved the final manuscript.

\section{Conflict of interest}

The authors declare no conflict of interest. 
Table 1 Reported cases of neuroblastoma suggestive of the GVT effect following allo-HSCT

\begin{tabular}{|c|c|c|c|c|c|c|c|c|}
\hline Author & $\begin{array}{l}\text { No. of } \\
\text { patients }\end{array}$ & $\begin{array}{l}\text { Patient's status } \\
\text { at HSCT }\end{array}$ & $\begin{array}{l}\text { Stem cell } \\
\text { source }\end{array}$ & Conditioning & Acute GVHD & $\begin{array}{l}\text { Chronic } \\
\text { GVHD }\end{array}$ & $\begin{array}{l}\text { Post-HSCT } \\
\text { treatment }\end{array}$ & Outcome \\
\hline Inoue et al. ${ }^{7}$ & 1 & 1st PR & Haploidentical & MAC & Grade I & No & Chemotherapy & Alive (CR: 4 y) \\
\hline Hirayama et al. ${ }^{a}$ & 1 & 2nd CR & MRD PBSC & RIC & Grade III & Extensive & No & Alive (CR: $30 \mathrm{~m}$ ) \\
\hline Marabelle et al. ${ }^{\mathrm{b}}$ & 1 & 2nd PR & MUD BM & RIC & Grade II & Limited & No & Alive (CR: $30 \mathrm{~m}$ ) \\
\hline Kanold et al. ${ }^{\circ}$ & 2 & 1st PR & MRD BM & RIC & Grade III, No & No & DLI & $\begin{array}{l}\text { Alive (CR: } 38 \mathrm{~m} \text { ), } \\
\text { Dead (PD: } 4 \mathrm{~m} \text { ) }\end{array}$ \\
\hline Yoshida et al. ${ }^{9}$ & 1 & $\begin{array}{l}\text { 2nd PR (DLI: } \\
\text { 2nd relapse) }\end{array}$ & MRD BM & MAC & No & No & $\begin{array}{l}\text { DLI, CD4 }{ }^{+} \text {DLI, } \\
\text { Chemotherapy }\end{array}$ & Dead (PD: 8 m) \\
\hline Toporski et al. ${ }^{d}$ & 2 & $\begin{array}{l}\text { 2nd CR, } \\
\text { 2nd PR }\end{array}$ & Haploidentical & RIC, MIBG & Grade II & No & DLI & $\begin{array}{l}\text { Alive (CR: } 40 \text { m, } \\
\text { PR: } 42 \mathrm{~m} \text { ) }\end{array}$ \\
\hline Sung et al. ${ }^{e}$ & 2 & $\begin{array}{l}\text { 2nd VGPR, } \\
\text { 2nd MR }\end{array}$ & $\begin{array}{l}\text { MRD BM, } \\
\text { MUD BM }\end{array}$ & RIC & Grade II & $\begin{array}{l}\text { Extensive, } \\
\mathrm{NE}\end{array}$ & No & $\begin{array}{l}\text { Dead (PD: } 8 \mathrm{~m} \text {, } \\
\text { viral myocarditis: } \\
3 \mathrm{~m} \text { ) }\end{array}$ \\
\hline Goi et al. ${ }^{f}$ & 3 & $\begin{array}{l}\text { 1st VGPR (2), } \\
\text { 1st PR (1) }\end{array}$ & $\begin{array}{l}\text { UCB (2), } \\
\text { RCB (1) }\end{array}$ & Tandem & $\begin{array}{l}\text { Grade I, II, } \\
\text { No }\end{array}$ & $\begin{array}{l}\text { Limited (1), } \\
\text { No (2) }\end{array}$ & No & $\begin{array}{l}\text { Alive (CR: } 37 \\
56,60 \mathrm{~m} \text { ) }\end{array}$ \\
\hline Kanold et al. ${ }^{9}$ & 1 & 1st PR & Haploidentical & RIC & Grade II & No & $\begin{array}{l}\text { DNKI, } \\
\text { Chemotherapy }\end{array}$ & Alive (CR: $31 \mathrm{~m}$ ) \\
\hline Sato et al. ${ }^{\mathrm{h}}$ & 1 & 1st PR & UCB & RIC, MIBG & Grade II & No & No & Dead (NA: $12 \mathrm{~m}$ ) \\
\hline Our patient & 1 & 1st PR & MRD BM & MAC & Grade I & Extensive & No & Alive (CR: $80 \mathrm{~m}$ ) \\
\hline
\end{tabular}

HSCT, hematopoietic stem cell transplantation; PR, partial remission; CR, complete remission; VGPR; very good partial remission; MR, mixed response; MUD, matched unrelated donor; BM, bone marrow; MRD, matched related donor; PBSC, peripheral blood stem cell; UCB, unrelated cord blood; RCB, related cord blood; MAC, myeloablative conditioning; RIC, reduced-intensity conditioning; MIBG, metaiodobenzyl-guanidine; GVHD, graft versus host disease; NE, not evaluated; DLI, donor lymphocyte infusion; DNKI, donor NK cell infusion; y, years; m, months; NA, not available

References (a to $\mathrm{h}$ ) are described in supplemental data.

\section{References}

1. Maris JM, Hogarty MD, Bagatell R, Cohn SL. Neuroblastoma. Lancet. 2007; 369: 2106-2120.

2. Park JR, Bagatell R, London WB, et al. Children's Oncology Group's 2013 blueprint for research: neuroblastoma. Pediatr Blood Cancer. 2013; 60: 985-993.

3. Sung KW, Son MH, Lee SH, et al. Tandem high-dose chemotherapy and autologous stem cell transplantation in patients with high-risk neuroblastoma: results of SMC NB2004 study. Bone Marrow Transplant. 2013; 48: 68-73.

4. Horowitz MM, Gale RP, Sondel PM, et al. Graft-versusleukemia reactions after bone marrow transplantation. Blood. 1990; 75: 555-562.

5. Kolb HJ, Schattenberg A, Goldman JM, et al. Graft-versusleukemia effect of donor lymphocyte transfusions in marrow grafted patients. Blood. 1995; 86: 2041-2050.

6. Childs R, Chernoff A, Contentin N, et al. Regression of metastatic renal-cell carcinoma after nonmyeloablative allogeneic peripheral-blood stem-cell transplantation. N Engl J Med. 2000; 343: 750-758.

7. Inoue M, Nakano T, Yoneda A, et al. Graft-versus-tumor effect in a patient with advanced neuroblastoma who received HLA haplo-identical bone marrow transplantation. Bone
Marrow Transplant. 2003; 32: 103-106.

8. Hale GA, Arora M, Ahn KW, et al. Allogeneic hematopoietic cell transplantation for neuroblastoma: the CIBMTR experience. Bone Marrow Transplant. 2013; 48: 1056-1064.

9. Yoshida H, Kusuki S, Hashii Y, et al. Ex vivo-expanded donor CD4(+) lymphocyte infusion against relapsing neuroblastoma: A transient graft-versus-tumor effect. Pediatr Blood Cancer. 2009; 52: 895-897.

10. Valcárcel D, Martino R, Caballero D, et al. Sustained remissions of high-risk acute myeloid leukemia and myelodysplastic syndrome after reduced-intensity conditioning allogeneic hematopoietic transplantation: chronic graft-versus-host disease is the strongest factor improving survival. J ClinOncol. 2008; 26: 577-584.

11. Barkholt L, Bregni M, Remberger M, et al. Allogeneic haematopoietic stem cell transplantation for metastatic renal carcinoma in Europe. Ann Oncol. 2006; 17: 1134-1140.

12. Bay JO, Cabrespine-Faugeras A, Tabrizi R, et al. Allogeneic hematopoietic stem cell transplantation in ovarian cancer-the EBMT experience. Int J Cancer. 2010; 127: 1446-1452.

13. Meunier MC, Delisle JS, Bergeron J, et al. T cells targeted against a single minor histocompatibility antigen can cure solid tumors. Nat Med. 2005; 11: 1222-1229.

14. Ash S, Gigi V, Askenasy N, et al. Graft versus neuroblastoma 
reaction is efficiently elicited by allogeneic bone marrow transplantation through cytolytic activity in the absence of GVHD. Cancer Immunol Immunother. 2009; 58: 2073-2084.

15. Wölfl M, Jungbluth AA, Garrido F, et al. Expression of MHC class I, MHC class II, and cancer germline antigens in neuroblastoma. Cancer Immunol Immunother. 2005; 54: 400406.

\section{Supplemental data References}

a. Hirayama M, Azuma E, Araki M, Komada Y, Nakagawa A. Evidence of graft-versus-tumor effect in refractory metastatic neuroblastoma. Transplantation. 2006; 82: 142-144.

b. Marabelle A, Paillard C, Tchirkov A, et al. Graft-versustumour effect in refractory metastatic neuroblastoma. Bone Marrow Transplant. 2007; 39: 809-810.

c. Kanold J, Paillard C, Tchirkov A, et al. Allogeneic or haploidentical HSCT for refractory or relapsed solid tumors in children: toward a neuroblastoma model. Bone Marrow Transplant. 2008; 42 (Suppl. 2): 25-30. d. Toporski J, Garkavij M, Tennvall J, et al. High-dose iodine131-metaiodobenzylguanidine with haploidentical stem cell transplantation and posttransplant immunotherapy in children with relapsed/refractory neuroblastoma. Biol Blood Marrow Transplant. 2009; 15: 1077-1085.

e. Sung KW, Park JE, Chueh HW, et al. Reduced-intensity allogeneic stem cell transplantation for children with neuroblastoma who failed tandem autologous stem cell transplantation. Pediatr Blood Cancer 2011; 57: 660-665.

f. Goi K, Inukai T, Honna H, et al. Successful tandem (autologous-cord blood) SCT in advanced neuroblastomas with highly amplified MYCN. Bone Marrow Transplant. 2011; 46: 835-839.

g. Kanold J, Paillard C, Tchirkov A, et al. NK cell immunotherapy for high-risk neuroblastoma relapse after haploidentical HSCT. Pediatr Blood Cancer. 2012; 59: 739742.

h. Sato Y, Kurosawa H, Fukushima K, et al. I-131metaiodobenzylguanidine therapy with allogeneic cord blood stem cell transplantation for recurrent neuroblastoma. Ital J Pediatr. 2012; 38: 53. 